\title{
Bradyrhizobium canariense sp. nov., an acid- tolerant endosymbiont that nodulates endemic genistoid legumes (Papilionoideae: Genisteae) from the Canary Islands, along with Bradyrhizobium japonicum bv. genistearum, Bradyrhizobium geno- species alpha and Bradyrhizobium genospecies beta
}

Correspondence

Pablo Vinuesa

vinuesa@ccg.unam.mx

Published online ahead of print on 24 September 2004 as DOI 10.1099/ijs.0.63292-0.

Abbreviations: ECGL, endemic Canarian genistoid legume; REP, repetitive extragenic palindromic sequence.

The GenBank/EMBL/DDBJ accession number for the rrs sequence of strain BC-C2 is AY577427; those for the ITS1 sequences are AY386703AY386705, AY386707, AY386708, AY386712-AY386718, AY386721, AY386722, AY386734, AY599094 and AY599095.

Sequence accession numbers for new Bradyrhizobium sequences used and generated in this study, the figures discussed in the text and our final and concluding remarks are available as supplementary material in IJSEM Online. 
In previous reports, we have shown that at least four Bradyrhizobium lineages nodulate endemic genistoid legumes such as Adenocarpus, Chamaecytisus, Lupinus, Spartocytisus and Teline species in soils of the Canary Islands (Fig. A, available as supplementary material in IJSEM Online). They are consistently distinguished by PCR-RFLPs of $r r s+$ ITS amplicons (Jarabo-Lorenzo et al., 2003; Vinuesa et al., 1998, 1999), profiling of stable lowmolecular-weight RNAs (Jarabo-Lorenzo et al., 2000) and phylogenetic analyses of ITS (Fig. B, available as supplementary material in IJSEM Online), atpD, glnII and recA sequences using maximum-likelihood and Bayesian inference methods (Vinuesa et al., 2005). We have shown that these lineages can be also recovered from the nodules of other genistoid legumes such as Lupinus spp. and from Ornithopus spp. (Papilionoideae: Loteae) growing in Africa, Europe and America (Jarabo-Lorenzo et al., 2003; Vinuesa \& Silva, 2004; Vinuesa et al., 2005), using diverse complex media containing yeast-extract and mannitol such as YMA or $20 \mathrm{E}$ and following standard isolation procedures (LeónBarrios et al., 1991; Vinuesa et al., 1998).

Bradyrhizobium japonicum is one of the lineages that nodulates endemic Canarian genistoid legumes (ECGLs) (Vinuesa et al., 2005). The other three lineages represent unnamed genospecies that are clearly delineated in a well resolved species phylogeny based on combined $g \ln I I+\operatorname{rec} A$ sequences (see Fig. C, available as supplementary material in IJSEM Online).

Here we present evidence for the taxonomic distinctiveness (Stackebrandt et al., 2002; Vandamme et al., 1996) of one of these evolutionary lineages, for which we propose the name Bradyrhizobium canariense. This species can be unequivocally distinguished from the five Bradyrhizobium species currently described, namely B. japonicum (Jordan, 1982, 1984), Bradyrhizobium elkanii (Kuykendall et al., 1992), Bradyrhizobium liaoningense (Xu et al., 1995), Bradyrhizobium yuanmingense (Yao et al., 2002) and Bradyrhizobium betae (Rivas et al., 2004), by a combination of genotypic, physiological and ecological characteristics. $B$. betae was recently isolated from tumour-like root deformations of sugar beet (Beta vulgaris) in Northern Spain and has an unknown symbiotic status. It is possible that the four isolates used for the species description actually represent a single clone, since all presented the same ITS haplotype (Rivas et al., 2004). B. yuanmingense was isolated from the root nodules of Lespedeza spp. growing in China, whereas the other three species were isolated from the nodules of soybean (Glycine max) in different continents (see Table A and figures provided as supplementary material in IJSEM Online).

B. canariense strains are grouped in highly supported monophyletic clusters in the gene trees inferred from a large number of ITS (Fig. B in IJSEM Online), atpD, glnII and recA sequences obtained from isolates of ECGLs and a diverse worldwide collection of Bradyrhizobium strains, including the type strains of all previously described species in the genus (Vinuesa et al., 2005). Population genetics studies of Moroccan and Canarian B. canariense isolates (Vinuesa et al., 2005) based on repetitive extragenic palindromic sequence (REP)-PCR genomic fingerprints, multilocus enzyme electrophoresis (MLEE) and multilocus sequence $(a t p D, g \ln I I, \operatorname{rec} A)$ polymorphisms revealed: i) high levels of strain diversity across sampling sites; ii) significant levels of recombination, as assessed by linkage disequilibrium analyses of MLEE data, variance- and coalescent-based estimation methods of the population recombination parameter, and the reticulated evolutionary pattern exhibited by the ITS, atpD, $g \ln I I$ and $r e c A$ sequence partitions; iii) lack of genetic differentiation between continental and insular populations; and iv) significant gene flow between them. From these findings it was inferred that migration and recombination are significant evolutionary forces that provide $B$. canariense with internal cohesiveness and shape its genetic population structure (Vinuesa \& Silva, 2004; Vinuesa et al., 2005). Furthermore, these population genetics studies revealed that there is no significant recombination between $B$. canariense strains and the other three sympatric evolutionary lineages recovered from the nodules of ECGLs, and that the genetic differentiation between these lineages is highly significant (Vinuesa et al., 2005). This finding is remarkable since the four species have overlapped ecological niches and therefore the ecological opportunity for horizontal gene transfer. In conclusion, these studies demonstrated that $B$. canariense represents a bona fide evolutionary, phylogenetic and cohesive species (Mayr, 1970; Templeton, 1989; Ward, 1998; Wiley, 1978).

Horizontal gene transfer was detected across $B$. canariense and B. japonicum at the symbiotic nifH and nodCloci, which map more than $250 \mathrm{~kb}$ apart one from the other on the chromosomal symbiotic region of B. japonicum USDA 110 (Göttfert et al., 2001; Kaneko et al., 2002). The nifH and nodC phylogenies correlated well with the host range of the ECGL isolates (Jarabo-Lorenzo et al., 2003; Vinuesa et al., 2005), but were incongruent with the maximum-likelihood species phylogeny (Felsenstein, 2004; Nichols, 2001) inferred from combined and congruent glnII plus recA (compare Figs $C$ and $D$, available as supplementary material in IJSEM Online) partitions (Vinuesa et al., 2005). Regardless of their geographical origin and (geno)species assignation, all isolates from genistoid legumes and Ornithopus spp. contained nifH and nodC alleles that were recovered in highly supported clades in the corresponding gene trees (see Fig. Da and $\mathrm{Db}$ in IJSEM Online), highlighting the independent evolutionary histories of adaptative (accessory) and housekeeping (core) loci (Lan \& Reeves, 2000; Wernegreen \& Riley, 1999). The most parsimonious explanation for the observed phylogenetic incongruence between housekeeping and sym loci is that lateral transfer events of symbiotic islands took place across species, probably mediated by an illegitimate recombination mechanism (Kaneko et al., 2002; Sullivan \& Ronson, 1998). Therefore, phylogenetic analysis of these two symbiotic genes, coupled with host-range experiments (Table 1), allowed us to uncover and delineate 
Table 1. Host-range experiments performed in Leonard jars using selected Bradyrhizobium strains and legume hosts

\begin{tabular}{|c|c|c|c|c|c|c|}
\hline Bradyrhizobium species, biovar and strain ${ }^{\star}$ & \multicolumn{6}{|c|}{ Host $\dagger$} \\
\hline B. canariense bv. genistearum $\mathrm{BC}-\mathrm{C} 2$ & $\mathrm{Fix}^{+}$ & $\mathrm{Fix}^{+}$ & $\mathrm{Fix}^{+}$ & $\mathrm{Nod}^{-}$ & $\mathrm{Nod}^{-}$ & $\mathrm{Fix}^{+/-}$ \\
\hline B. canariense bv. genistearum BC-MAM1 & $\mathrm{Fix}^{+}$ & $\mathrm{Fix}^{+}$ & $\mathrm{Fix}^{+}$ & $\mathrm{Nod}^{-}$ & $\mathrm{Nod}^{-}$ & $\mathrm{Fix}^{+/-}$ \\
\hline B. canariense bv. genistearum ISLU16 & $\mathrm{Fix}^{+}$ & $\mathrm{Fix}^{+}$ & $\mathrm{Fix}^{+}$ & $\mathrm{Nod}^{-}$ & $\mathrm{Nod}^{-}$ & ND \\
\hline B. japonicum bv. genistearum Blup-MR1 & $\mathrm{Fix}^{+}$ & $\mathrm{Fix}^{+}$ & $\mathrm{Fix}^{+}$ & $\mathrm{Nod}^{-}$ & $\mathrm{Nod}^{-}$ & $\mathrm{ND}$ \\
\hline B. japonicum bv. glycinearum USDA 110 & $\mathrm{Nod}^{-}$ & $\mathrm{Nod}^{-}$ & $\mathrm{Nod}^{-}$ & $\mathrm{Fix}^{+}$ & $\mathrm{Fix}^{+}$ & $\mathrm{Fix}^{+}$ \\
\hline B. japonicum bv. glycinearum DSM $30131^{\mathrm{T}}$ & $\mathrm{Nod}^{-}$ & $\mathrm{Nod}^{-}$ & $\operatorname{Nod}^{-}$ & $\mathrm{Fix}^{+}$ & $\mathrm{Fix}^{+}$ & $\mathrm{Fix}^{+/-}$ \\
\hline B. liaoningense bv. glycinearum LMG $18230^{\mathrm{T}}$ & $\mathrm{Nod}^{-}$ & $\mathrm{Nod}^{-}$ & $\mathrm{Nod}^{-}$ & $\mathrm{Fix}^{+}$ & ND & ND \\
\hline B. yuanmingense CCBAU $10071^{\mathrm{T}}$ & $\mathrm{Nod}^{-}$ & $\mathrm{Nod}^{-}$ & $\mathrm{Nod}^{-}$ & $\mathrm{Nod}^{-}$ & ND & $\mathrm{ND}$ \\
\hline
\end{tabular}

${ }^{*}$ Species and biovar assignation of strains is supported by the ITS, $g \ln I I+\operatorname{rec} A$, niH and nodC phylogenies presented in Figs B, C and D (available as supplementary material in IJSEM Online) and further evidence presented in Vinuesa et al. (2005).

$\dagger$ C. proliferus, T. canariense, L. luteus, G. max, G. soja and M. atropurpureum are species of the genera Chamaecytisus, Teline, Lupinus, Glycine and Macroptilium, respectively.

$¥ \mathrm{Fix}^{+}$indicates a nitrogen-fixing symbiosis, as revealed by the acetylene reduction assay; $\mathrm{Fix}^{+/-}$indicates weak levels of acetylene reduction; $\mathrm{Nod}^{-}$indicates a non-nodulating interaction; ND, not determined. Plant germination, inoculation and cultivation were as described previously (Vinuesa et al., 1998).

for the first time Bradyrhizobium biovarieties (symbiotic ecotypes, Fig. D in IJSEM Online), as defined in Vinuesa et al. (2005), and according to the proposed minimal standards for the description of new genera and species of root- and stem-nodulating bacteria (Graham et al., 1991). These biovarieties should not be confounded with new species on the basis of their symbiotic (host range) phenotypes (Graham et al., 1991; Lan \& Reeves, 2001). We agree with Graham et al. (1991) that species descriptions of symbiotic rhizobia should be accompanied by a definition of their biovariety in the form of a latin trinomial, although we disagree with the proposal of equating each ecotype with a new species (Cohan, 2002), since the ecological characters conferred by symbiotic plasmids or islands are highly prone to rapid gain and loss events and horizontal transfer, and well delineated evolutionary species, such as B. japonicum, have more than one biovariety (see Fig. Da and Db in IJSEM Online).

An estimate of the Bradyrhizobium species phylogeny (Felsenstein, 2004; Nichols, 2001) based on a maximumlikelihood analysis of congruent $g \ln I I+r e c A$ sequence partitions (Fig. $C$ in IJSEM Online) provided strong evidence that $B$. canariense is the sister species of $B$. japonicum, which is consistent with a Bayesian phylogeny presented elsewhere (Vinuesa et al., 2005). This species phylogeny is congruent with the current taxonomy of the genus. Only the position of $B$. betae remains uncertain because rrs and ITS sequences do not resolve its phylogenetic placement (see Figs B and $\mathrm{E}$, available as supplementary material in IJSEM Online) and protein-coding gene sequences are not available for this taxon yet. Importantly, the $g \ln I I+r e c A$ species phylogeny (see Fig. $\mathrm{C}$ and the final and concluding remarks in IJSEM Online) does not provide conclusive support to the hypotheses derived from numerical taxonomy and $r r s$ sequence analyses that the photosynthetic bradyrhizobia and B. elkanii may represent new genera (Ladha \& So, 1994; van Berkum \& Eardly, 1998; Willems et al., 2001b). Taking a more conservative classification criterion based on a consensus of the different data sources available at the moment for these bacteria, and considering the topology presented in Fig. C, favours their classification as basal lineages of the genus Bradyrhizobium (see the final and concluding remarks in IJSEM Online), which supports the conclusions reached by So et al. (1994) based on rrs and fatty acid analysis that they are bradyrhizobia, as well as the old hypothesis of a photosynthetic ancestor for the genus (Jarvis et al., 1986; Vinuesa et al., 2005).

It had been shown previously that ITS sequence clades correlate reasonably well with DNA-homology groups (Willems et al., 2001a, 2003). Therefore, we used the topologies inferred from the ITS and $g \ln I I+r e c A$ sequence data (Figs B and C in IJSEM Online) to select a number of representative $B$ canariense, $B$. japonicum and $B$. liaoningense strains to perform DNA-DNA hybridization experiments, using a filter hybridization (dot-blot) technique. Three replicate samples of $2 \mu \mathrm{g}$ of purified genomic DNA (genomic DNA purification kit; Roche Molecular Biochemicals) were vacuum-blotted onto nylon membranes and cross-linked with UV light. Five-hundred nanograms of purified genomic DNA from three distinct $B$. canariense strains (BC-C2, BES-1 and BTA- $1^{\mathrm{T}}$ ) were randomly labelled with digoxigenin using the DIG-labelling system (Roche 
Table 2. Percentage of relative DNA-DNA hybridization obtained between Bradyrhizobium canariense BC-C2, BES-1 and $\mathrm{BTA}-1^{\top}$, conspecific isolates and selected $B$. japonicum and $B$. liaoningense strains

\begin{tabular}{|c|c|c|c|c|}
\hline \multirow[t]{2}{*}{ Bradyrhizobium species, biovar and strain } & \multicolumn{3}{|c|}{ DNA homology (\%) with probe: } & \multirow[t]{2}{*}{ Avg.* } \\
\hline & BC-C2 & BES-1 & BTA-1 ${ }^{\mathrm{T}}$ & \\
\hline B. canariense bv. genistearum $\mathrm{BC}-\mathrm{C} 2$ & 100 & $85 \pm 5$ & $81 \pm 3$ & \multirow{7}{*}{$82 \cdot 9 \pm 9 \cdot 5, n=18$} \\
\hline B. canariense bv. genistearum BES-1 & $74 \pm 4$ & 100 & $88 \pm 4$ & \\
\hline B. canariense bv. genistearum BTA- $1^{\mathrm{T}}$ & $70 \pm 3$ & $85 \pm 3$ & 100 & \\
\hline B. canariense bv. genistearum $\mathrm{BC}-\mathrm{P} 1$ & $76 \pm 3$ & $84 \pm 4$ & $84 \pm 4$ & \\
\hline B. canariense bv. genistearum BC-P5 & $69 \pm 1$ & $81 \pm 3$ & $80 \pm 2$ & \\
\hline B. canariense bv. genistearum BC-MAM1 & $84 \pm 3$ & $73 \pm 4$ & $78 \pm 5$ & \\
\hline B. japonicum bv. genistearum BGA-1 & $38 \pm 6$ & $41 \pm 2$ & $46 \pm 4$ & \\
\hline B. japonicum bv. glycinearum DSM $30131^{\mathrm{T}}$ & $24 \pm 3$ & $41 \pm 4$ & $39 \pm 2$ & \multirow{3}{*}{$34 \cdot 9 \pm 10 \cdot 6, n=12$} \\
\hline B. japonicum bv. glycinearum USDA 110 & $13 \pm 6$ & $34 \pm 4$ & $30 \pm 7$ & \\
\hline B. japonicum bv. glycinearum X6-9 & $22 \pm 4$ & $47 \pm 3$ & $44 \pm 4 J$ & \\
\hline B. liaoningense bv. glycinearum LMG $18230^{\mathrm{T}}$ & $25 \pm 5$ & $48 \pm 9$ & $37 \pm 6\}$ & \multirow{2}{*}{$33 \cdot 2 \pm 10 \cdot 4, n=6$} \\
\hline B. liaoningense Spr3-7 & $19 \pm 3$ & $39 \pm 8$ & $31 \pm 6$ & \\
\hline
\end{tabular}

*Avg., average percentage of DNA hybridization signal among strains for the number $(n)$ of comparisons indicated.

Molecular Biochemicals) and used as probes (adjusted to $20 \mathrm{ng} \mathrm{ml}^{-1}$ in the hybridization solution). Stringent hybridization was carried out overnight at $68^{\circ} \mathrm{C}$, followed by high-stringency washings at $68^{\circ} \mathrm{C}$ in $0.5 \times$ SSC. Hybridization signals were detected by chemiluminiscence using anti DIG Fab fragments and the enhanced chemifluorescence substrate (Roche Molecular Biochemicals), and quantified using a Storm 860 phosphorimager (Molecular Dynamics) equipped with the ImageQuant software (Amersham Pharmacia Biotech). The hybridization results are shown in Table 2 and indicated that the three probes hybridized significantly stronger (in the 69-88\% range) with $B$. canariense isolates than with $B$. japonicum and $B$. liaoningense strains (13-48\% range).

B. canariense strains can be further distinguished from all other described Bradyrhizobium species by a combination of genotypic, physiological and ecological traits, as indicated in the species description. Distinctive phenotypic features of $B$. canariense are presented in Table 3 . It should be noted, however, that such phenotypic traits are highly inconsistent when large populations are studied $(\mathrm{Xu}$ et al.,

Table 3. Distinctive phenotypic features for Bradyrhizobium canariense and reference Bradyrhizobium species

Species: 1, B. canariense; 2, B. japonicum; 3, B. elkanii; 4, B. liaoningense; 5, B. yuanmingense; 6, B. betae. Data for B. japonicum, B. elkanii and B. yuanmingense were taken from Table 3 of Yao et al. (2002), data for B. liaoningense from Xu et al. (1995), and data for B. betae from Rivas et al. (2004). +, >95\% of isolates were positive;,$->95 \%$ of the isolates were negative; $+/-$, variable; NR, not reported.

\begin{tabular}{|c|c|c|c|c|c|c|}
\hline Characteristics & 1 & 2 & 3 & 4 & 5 & 6 \\
\hline \multicolumn{7}{|l|}{ C sources: } \\
\hline D-Fructose & + & $-{ }^{\star}$ & + & $+1-$ & - & $+1-$ \\
\hline Maltose/sucrose & - & $+^{*}$ & $+^{*}$ & - & $+1-$ & $+1-$ \\
\hline \multicolumn{7}{|l|}{ N source: } \\
\hline Erythromycin $\left(100 \mu \mathrm{g} \mathrm{ml}^{-1}\right)$ & $+1-$ & $-{ }^{*}$ & + & NR & - & $+1-$ \\
\hline \multicolumn{7}{|l|}{ Growth characteristics: } \\
\hline $\mathrm{pH} 4 \cdot 5$ & + & - & + & NR & - & NR \\
\hline $\mathrm{pH} 10$ & - & - & $+1-$ & - & - & NR \\
\hline $1 \cdot 0 \% \mathrm{NaCl}$ & - & $+^{*}$ & $+^{*}$ & - & - & + \\
\hline
\end{tabular}

${ }^{\star}$ Our own data are not consistent with those reported previously. 
1995; Yao et al., 2002), and it is well documented that phenotypic and genotypic clustering of Bradyrhizobium strains correlates poorly (Dupuy et al., 1994; So et al., 1994; van Rossum et al., 1995; Zhang et al., 1999).

The description of Bradyrhizobium canariense sp. nov. is therefore supported by the population genetics, phylogenetic, DNA homology, physiological and ecological evidence presented above. This is the first description of a novel root nodule microsymbiont species that is primarily based on molecular evolutionary criteria, using a large collection of strains from different hosts and geographical origins, which have been extensively characterized by a broad range of genotyping methods (REP-PCR, rrs + ITS PCR-RFLPs, MLEE and stable low-molecular-weight RNAs), as well as by state-of-the-art phylogenetic methods using seven gene partitions [five informational/housekeeping loci ( $r r s$, ITS, atpD, glnII and recA) and two sym loci (nifH and $\operatorname{nod}())$. Therefore, this work follows the recommendations made by the ad hoc committee for the re-evaluation of the species definition in bacteriology (Stackebrandt et al., 2002). Furthermore, it augments and actualizes the proposed minimal standards for the description of new genera and species of root- and stem-nodulating bacteria (Graham et al., 1991) by the use of more advanced analytical tools, a highly resolved Bradyrhizobium species phylogeny and an updated theoretical framework. Finally, in view of the richness of evolutionary and ecological inferences that can be made from sequence data (see the final and concluding remarks provided in IJSEM Online), we would like to encourage (brady)rhizobial taxonomists to make more extensive use of them in future works. In doing so, a large multilocus sequence database could be built up quickly and used as the primary source of characters for molecular evolutionary and systematic studies. Only sequence data are highly portable and freely exchangeable by different researchers for unambiguous comparative analyses.

\section{Description of Bradyrhizobium canariense sp. nov.}

Bradyrhizobium canariense [ca.na.ri.en'se. N.L. neut. adj. canariense pertaining to the Canary Islands (Islas Canarias), where it is the dominant species nodulating endemic shrub legumes Papilionoideae: Genisteae].

Gram-negative, aerobic, slow-growing, non-spore-forming rods, as for other species of the genus, motile by a single subpolar flagellum (León-Barrios et al., 1991). Phenotypically, B. canariense strains are highly diverse. Colonies on YMA ( $\mathrm{pH} 6 \cdot 8$ ) are white or creamy, $1-1.5 \mathrm{~mm}$ in diameter after 7 days incubation at $28^{\circ} \mathrm{C}$, producing an acid reaction and variable amounts of exopolysaccharides, as reflected by the diverse textures, consistencies and growth patterns they exhibit on solid media. Their lipopolysaccharide (LPS) $\mathrm{O}$-antigens are also highly diverse as determined by DOCPAGE analysis of purified LPSs and immunological crossreactions (León-Barrios et al., 1991; Santamaría et al., 1997). Optimum growth temperature is $28-30^{\circ} \mathrm{C}$, but inhibited at $37^{\circ} \mathrm{C}$. No growth is observed at $\mathrm{pH} 9$, or in the presence of $1 \% \mathrm{NaCl}$ on YMA. They use $(+)$-D-glucose, $(+)$-Dmannose, (+)-D-galactose, (-)-D-fructose, (-)-L-rhamnose, (+)-D-xylose, (-)-D-ribose, (-)-D-arabinose, glycerol, mannitol, sorbitol, citrate, fumarate and succinate, but not (-)-L-sorbose, melibiose, lactose, sucrose, (+)-Dtrehalose, inulin, starch or catechol as sole carbon sources. Use L-glutamine but not L-glycine as sole $\mathrm{N}$ source. They are highly acid-tolerant, forming colonies of $1 \mathrm{~mm}$ in diameter after 6 to 7 days incubation at $30^{\circ} \mathrm{C}$ on acidified $20 \mathrm{E}$ plates at $\mathrm{pH} 4 \cdot 2$ solidified with GelRite (Roth, Germany) and buffered with $25 \mathrm{mM}$ Homopipes (Vinuesa et al., 2003). The symbiotic genes map to the chromosome, lacking plasmids as revealed by Eckhardt gelelectrophoresis (Eckhardt, 1978). Its known geographical distribution includes Spain, Morocco, the Canary Islands and the Americas. A single biovariety (bv. genistearum) is presently known, which nodulates different genera and species in the legume tribe Genisteae (e.g. Lupinus spp., Adenocarpus spp., Chamaecytisus proliferus, Spartocytisus supranubius and Teline spp.), as well as Ornithopus spp. (Papilionoideae: Loteae), but does not nodulate soybeans (Glycine max or Glycine soja, Papilionoideae: Phaseoleae). At the molecular level this species can be easily distinguished from strains of its sister species B. japonicum and all other described Bradyrhizobium species by the unique 16S rRNA PCR-RFLP genotype obtained with the endonucleases HhaI, DdeI and Hinfl (Jarabo-Lorenzo et al., 2000, 2003; Vinuesa et al., 1998, 1999, 2005). B. canariense strains also display a distinct fingerprint of stable low-molecular-weight RNAs (Jarabo-Lorenzo et al., 2000). It forms statistically highly supported ITS, atpD, glnII and recA sequence clades under the maximum-likelihood optimality criterion using best-fit models of nucleotide substitution (with bootstrap support $>90 \%$ in all cases). B. canariense strains are only weakly clonal, with significant recombination taking place within populations. DNA homology is greater than $69 \%$ between B. canariense strains, and lower than $50 \%$ with $B$. japonicum or $B$. liaoningense strains, its closest phylogenetic relatives.

The type strain, BTA- $1^{\mathrm{T}}\left(=\mathrm{ATCC}\right.$ BAA $-1002^{\mathrm{T}}=\mathrm{LMG}$ $22265^{\mathrm{T}}=$ CFNE $1008^{\mathrm{T}}$ ), was isolated from the root nodules of Chamaecytisus proliferus subsp. proliferus var. palmensis (Papilionoideae: Genisteae) in La Laguna, Tenerife, Canary Islands, Spain, and has a G $+\mathrm{C}$ content of $63.8 \mathrm{~mol} \%$. This and other B. canariense strains have been deposited at the strain collections of the CIFN-UNAM and the Departments of Microbiology at the Universities of La Laguna and Gent, from where they are freely available.

\section{Acknowledgements}

We gratefully acknowledge the excellent technical support received from Heidemarie Thierfelder and Eva-Maria Kurz (Philipps University, Marburg), Marco Antonio Rogel (CIFN-UNAM), René Hernández (IBT-UNAM) and Scott Bringham (ASU, Tempe, AZ). Mrs Ingrid Fleischmann and Mrs Anita Söllheim are thanked for their kind help during initial field work in the Canary Islands. Professor Dr Hans Trüper is acknowledged for his advice and help with Latin epithets. 
Holger Blasum, Jagdish K. Ladha, Kristina Lindström, Ernesto Ormeño and Peter van Berkum are thanked for providing strains. Partial financial support was obtained from UNAM-PAPIIT (Mexico), INCO DEV ICA4-CT-2001-10057 from the European Union and the DFG (Germany), in the SFB Project A6.

\section{References}

Cohan, F. M. (2002). What are bacterial species? Annu Rev Microbiol 56, 457-487.

Dupuy, N., Willems, A., Pot, B. \& 7 other authors (1994). Phenotypic and genotypic characterization of bradyrhizobia nodulating the leguminous tree Acacia albida. Int J Syst Bacteriol 44, 461-473.

Eckhardt, T. (1978). A rapid method for the identification of plasmid desoxyribonucleic acid in bacteria. Plasmid 1, 584-588.

Felsenstein, J. (2004). Inferring Phylogenies. Sunderland, MA: Sinauer Associates.

Göttfert, M., Rothlisberger, S., Kundig, C., Beck, C., Marty, R. \& Hennecke, H. (2001). Potential symbiosis-specific genes uncovered by sequencing a 410-kilobase DNA region of the Bradyrhizobium japonicum chromosome. J Bacteriol 183, 1405-1412.

Graham, P. H., Sadowsky, M. J., Keyser, H. H. \& 8 other authors (1991). Proposed minimal standards for the description of new genera and species of root- and stem-nodulating bacteria. Int J Syst Bacteriol 41, 582-587.

Jarabo-Lorenzo, A., Velazquez, E., Perez-Galdona, R., VegaHernandez, M. C., Martinez-Molina, E., Mateos, P. E., Vinuesa, P., Martinez-Romero, E. \& Leon-Barrios, M. (2000). Restriction fragment length polymorphism analysis of $16 \mathrm{~S} \mathrm{rDNA}$ and low molecular weight RNA profiling of rhizobial isolates from shrubby legumes endemic to the Canary Islands. Syst Appl Microbiol 23, $418-425$.

Jarabo-Lorenzo, A., Pérez-Galdona, R., Donate-Correa, J. \& 7 other authors (2003). Genetic diversity of bradyrhizobial populations from diverse geographic origins that nodulate Lupinus spp. and Ornithopus spp. Syst Appl Microbiol 26, 611-623.

Jarvis, B. D. W., Gillis, M. \& De Ley, J. (1986). Intra- and intergeneric similarities between the ribosomal ribonucleic acid cistrons of Rhizobium and Bradyrhizobium species and some related bacteria. Int J Syst Bacteriol 36, 129-138.

Jordan, D. C. (1982). Transfer of Rhizobium japonicum Buchanan 1980 to Bradyrhizobium gen. nov., a genus of slow-growing root nodule bacteria from leguminous plants. Int J Syst Bacteriol 32, 136-139.

Jordan, D. C. (1984). Family III. Rhizobiaceae Conn 1938. In Bergey's Manual of Systematic Bacteriology, pp. 234-244. Edited by N. R. Krieg \& J. G. Holt. Baltimore: Williams \& Wilkins.

Kaneko, T., Nakamura, Y., Sato, S. \& 14 other authors (2002). Complete genomic sequence of nitrogen-fixing symbiotic bacterium Bradyrhizobium japonicum USDA110. DNA Res 9, 189-197.

Kuykendall, L. D., Saxena, B., Devine, T. E. \& Udell, S. E. (1992). Genetic diversity in Bradyrhizobium japonicum Jordan 1982 and a proposal for Bradyrhizobium elkanii sp. nov. Can J Microbiol 38, 501-505.

Ladha, J. K. \& So, R. B. (1994). Numerical taxonomy of photosynthetic rhizobia nodulating Aeschynomene species. Int $J$ Syst Bacteriol 44, 62-73.

Lan, R. T. \& Reeves, P. R. (2000). Intraspecies variation in bacterial genomes: the need for a species genome concept. Trends Microbiol 8, 396-401.

Lan, R. \& Reeves, P. R. (2001). When does a clone deserve a name? A perspective on bacterial species based on population genetics. Trends Microbiol 9, 419-424.
León-Barrios, M., Gutiérrez-Navarro, A. M., Pérez-Galdona, R. \& Corzo, J. (1991). Characterization of Canary Island isolates of Bradyrhizobium sp. (Chamaecytisus proliferus). Soil Biol Biochem 23, 487-489.

Mayr, E. (1970). Populations, Species, and Evolution. Harvard University, MA: Belknap Press.

Nichols, R. (2001). Gene trees and species trees are not the same. Trends Ecol Evol 16, 358-364.

Rivas, R., Willems, A., Palomo, J. L., Garcia-Benavides, P., Mateos, P. F., Martínez-Molina, E., Gillis, M. \& Velázquez, E. (2004). Bradyrhizobium betae sp. nov., isolated from roots of Beta vulgaris affected by tumour-like deformations. Int J Syst Evol Microbiol 54, 1271-1275.

Santamaria, M., Corzo, J., León-Barrios, M. \& Gutiérrez-Navarro, A. M. (1997). Characterization and differentiation of indigenous rhizobia isolated from Canarian shrub legumes of agricultural and ecological interest. Plant Soil 190, 143-152.

So, R. B., Ladha, J. K. \& Young, J. P. (1994). Photosynthetic symbionts of Aeschynomene spp. form a cluster with bradyrhizobia on the basis of fatty acid and rRNA analyses. Int J Syst Bacteriol 44, 392-403.

Stackebrandt, E., Frederiksen, W., Garrity, G. M. \& 10 other authors (2002). Report of the ad hoc committee for the re-evaluation of the species definition in bacteriology. Int J Syst Evol Microbiol 52, 1043-1047.

Sullivan, J. T. \& Ronson, C. W. (1998). Evolution of rhizobia by acquisition of a $500-\mathrm{kb}$ symbiosis island that integrates into a phe-tRNA gene. Proc Natl Acad Sci U S A 95, 5145-5149.

Templeton, A. R. (1989). The meaning of species and speciation: a genetic perspective. In Speciation and its Consequences, pp. 3-27. Edited by D. Otte \& J. A. Endler. Sunderland, MA: Sinauer Associates.

van Berkum, P. \& Eardly, B. D. (1998). Molecular evolutionary systematics of the Rhizobiaceae. In The Rhizobiaceae: Molecular Biology of Plant-associated Bacteria, pp. 1-24. Edited by H. P. Spaink, A. Kondorosi \& P. J. J. Hooykaas. Dordrecht: Kluwer Academic.

Vandamme, P., Pot, B., Gillis, M., de Vos, P., Kersters, K. \& Swings, J. (1996). Polyphasic taxonomy, a consensus approach to bacterial systematics. Microbiol Rev 60, 407-438.

van Rossum, D., Schuurmans, F. P., Gillis, M., Muyotcha, A., Van Verseveld, H. W., Stouthamer, A. H. \& Boogerd, F. C. (1995). Genetic and phenetic analyses of Bradyrhizobium strains nodulating peanut (Arachis hypogaea L.) roots. Appl Environ Microbiol 61, 1599-1609.

Vinuesa, P. \& Silva, C. (2004). Species delineation and biogeography of symbiotic bacteria associated with cultivated and wild legumes. In Biological Resources and Migration, pp. 143-155. Edited by D. Werner. Berlin: Springer.

Vinuesa, P., Rademaker, J. L. W., de Bruijn, F. J. \& Werner, D. (1998). Genotypic characterization of Bradyrhizobium strains nodulating endemic woody legumes of the Canary Islands by PCR-restriction fragment length polymorphism analysis of genes encoding $16 \mathrm{~S}$ rRNA (16S rDNA) and 16S-23S rDNA intergenic spacers, repetitive extragenic palindromic PCR genomic fingerprinting and partial $16 \mathrm{~S}$ rDNA sequencing. Appl Environ Microbiol 64, 2096-2104.

Vinuesa, P., Rademaker, J. L. W., de Bruijn, F. J. \& Werner, D. (1999). Characterization of Bradyrhizobium spp. strains by RFLP analysis of amplified 16S rDNA and rDNA intergenic spacer regions. In Highlights on Nitrogen Fixation, pp. 275-279. Edited by E. Martínez \& G. Hernández. New York: Plenum.

Vinuesa, P., Neumann-Silkow, F., Pacios-Bras, C., Spaink, H. P., Martinez-Romero, E. \& Werner, D. (2003). Genetic analysis of a 
pH-regulated operon from Rhizobium tropici CIAT899 involved in acid tolerance and nodulation competitiveness. Mol Plant Microbe Interact 16, 159-168.

Vinuesa, P., Silva, C., Werner, D. \& Martínez-Romero, E. (2005). Population genetics and phylogenetic inference in bacterial molecular systematics: the roles of migration and recombination in Bradyrhizobium species cohesion and delineation. Mol Phylogenet Evol 34, 29-54.

Ward, D. M. (1998). A natural species concept for prokaryotes. Curr Opin Microbiol 1, 271-277.

Wernegreen, J. \& Riley, M. A. (1999). Comparison of the evolutionary dynamics of symbiotic and housekeeping loci: a case for the genetic coherence of rhizobial lineages. Mol Biol Evol 16, 98-113.

Wiley, E. (1978). The evolutionary species concept reconsidered. Syst Zool 27, 17-26.

Willems, A., Coopman, R. \& Gillis, M. (2001a). Comparison of sequence analysis of $16 \mathrm{~S}-23 \mathrm{~S}$ rDNA spacer regions, AFLP analysis and DNA-DNA hybridizations in Bradyrhizobium. Int $J$ Syst Evol Microbiol 51, 623-632.
Willems, A., Coopman, R. \& Gillis, M. (2001b). Phylogenetic and DNA-DNA hybridization analyses of Bradyrhizobium species. Int J Syst Evol Microbiol 51, 111-117.

Willems, A., Munive, A., de Lajudie, P. \& Gillis, M. (2003). In most Bradyrhizobium groups sequence comparison of 16S-23S rDNA internal transcribed spacer regions corroborates DNA-DNA hybridizations. Syst Appl Microbiol 26, 203-210.

Xu, L. M., Ge, C., Cui, Z., Li, J. \& Fan, H. (1995). Bradyrhizobium liaoningense sp. nov., isolated from the root nodules of soybeans. Int J Syst Bacteriol 45, 706-711.

Yao, Z. Y., Kan, F. L., Wang, E. T., Wei, G. H. \& Chen, W. X. (2002). Characterization of rhizobia that nodulate legume species of the genus Lespedeza and description of Bradyrhizobium yuanmingense sp. nov. Int J Syst Evol Microbiol 52, 2219-2230.

Zhang, X., Nick, G., Kaijalainen, S., Terefework, Z., Paulin, L., Tighe, S. W., Graham, P. H. \& Lindström, K. (1999). Phylogeny and diversity of Bradyrhizobium strains isolated from the root nodules of peanut (Arachis hypogaea) in Sichuan, China. Syst Appl Microbiol 22, 378-386. 